\title{
ANTIMICROBIAL ACTIVITY OF THE LEAF, FLOWER AND STEM EXTRACTS OF SPHENOCLEA ZEYLANICA
}

\author{
J. Gowri ${ }^{1 *}$, P.Arockia Sahayaraj ${ }^{2}$ and M Amaladasan ${ }^{3}$ \\ ${ }^{1}$ Department of Biotechnology Seethalakshmi Ramaswami College, Trichy-2, India \\ ${ }^{2} \mathrm{PG}$ and Research Department of Chemistry, Periyar E.V.R College, Trichy -23, India \\ ${ }^{3} \mathrm{PG}$ and Research Department of Chemistry, St. Joseph College, Tirchy-2, India \\ *Corresponding author email: gowrisai3@gmail.com
}

\begin{abstract}
The present study was carried out with an objective to investigate the antimicrobial potentials of leaves, flowers and stem extracts of Sphenoclea zeylanica. The aim of the study was to evaluate the antimicrobial activity and to determine the zone of inhibition of extracts against medically important bacterial and fungal strains. The antimicrobial activity was determined in the extracts using zone of inhibition method. The antibacterial and antifungal activities of extracts (40,50,60 and 70) of Sphenoclea zeylanica were tested against B. subtilis, P. vulgaris, S.aureus, E.coli, C. albicans, A. niger, S. typhi and B. cereus. Zone of inhibition of extracts were compared with that of control for antimicrobial activity. The results showed that the leaf extract showed notable inhibition of the microbial growth against the tested organisms. The microbial activity of the Sphenoclea zeylanic a might be due to the presence of various secondary metabolites. Hence, this plant can be used to identify the specific bioactive natural products which may serve as leads in the development of new antimicrobial agents.
\end{abstract}

Keywords: Sphenoclea zeylanica; Antimicrobial Activity; Antibiotic Resistance.

\section{Introduction}

Medicinal plants are a rich source of antimicrobial agents and are used as a source of many potent drugs (Srivastava et al., 1996). A range of medicinal plant parts possess varied medicinal properties and are used as raw drugs. Root, stem, flower, fruit, twigs exudates and modified plant organs are used. While some of these raw drugs are collected by the local communities and folk healers in smaller quantities, but some raw drugs are traded in the market as the raw material for many herbal industries and collected in larger quantities (Uniyal et al., 2006).

Despite hundreds of plants being tested for antimicrobial properties but still a vast majority of them have not been effectively assessed (Balandrin et al., 1985). Herbal medicines are used by about $75-80 \%$ of whole population, and involves the use of plant extract and their active constituents (Akerele, 1993). Though conventional drugs are widely used, herbal medicines are utilized due the presence of secondary metabolites such as alkaloids, flavonoids, tannins, and terpenoids reported to have antibacterial activities (Cowan, 1999; Adenkunle and Adekunle, 2009; Lewis and Ausubel, 2006).

Interest in medicinal plants has prospered due to the higher efficiency of plant derived drugs and the concern about the side effects of modern medicine. The resistance to antibiotic has increased substantially in the recent years. Usage of antibiotic resistance inhibitors from plants is one of the ways to reduce the antibiotic resistance (Kim et al., 1995; Alagesaboopathi, 2011). Plants produce a wide range of compounds in order to protect themselves against pathogens. The plant extracts which have target sites other than those used by antibiotics will be active against drug resistant pathogens (Ahmad and Beg, 2001). Antimicrobials derived from plants are a vast untapped source of medicines despite the studies on their wide spread therapeutic potential and effectiveness in the treatment of infectious disease, further research of plant antimicrobials are required (Parekh et al., 2007). The screening of plant extracts and their product has shown that higher plants are a potent source of novel antibiotics (Afolayan, 2003). Because of the availability of chemical diversity, natural products provide unlimited opportunities for the development of new drugs (Cos et al., 2006).

Though the discovery and development of antibiotics are the most important achievements of modern science and technology for controlling of infectious diseases. However, the rate of resistance of microorganisms tocommonly used anti-microbial agents is increasing with in startling 
frequency (Ge et al., 2002; Nair and Chanda, 2005; Neogi et al., 2008).

Fungal diseases are a critical health problem to health and are one of the main causes of morbidity and mortality worldwide (CSIR, 1998). In tropical and subtropical developing countries human infections, especially those of the skin and mucosal surfaces are a serious problem (Portillo et al; 2001). An alternative to the conventionally used fungicides is the use of compounds extracted from plants as they contain flavonoids, phenols, tannins, alkaloids, quinones, saponins and sterols (Burt, 2004).

Though the use of synthetic fungicides is a quick and effective management for most of plantpathogenic fungi their massive use has severe environmental impact (Osman and Al-Rehiayam, 2003). Their inappropriate use lead to adverse effects on ecosystems and also carcinogenic risk than insecticides and herbicides together (Stranger and Scott, 2005). Moreover, fungicides have become ineffective due to resistance by pathogens (Zhonghua and Michailides, 2005; Cohen, 1992; Nascimentoet al., 2000).

Sphenoclea zeylanica Gaertner belongs to family Campanulaceae, it is pantropical to India. It is found in swampy areas, along the banks of water courses and in rice fields. It is an erect annual herb, and the inflorescence is a dense, terminal spike with small, greenish yellow flowers. The young plants and tips of older plants are streamed and eaten as vegetable with rice in Java (Usher, 1984). In the present study, the methanol extract of Sphenoclea zeylanica leaf, stem and flower extracts were evaluated in order to know their antimicrobial activity against clinically important microorganisms.

\section{Materials and Methods}

\section{Screening of Antibacterial Activity}

\section{Preparation of Inoculums}

Stock cultures were maintained at $4{ }^{\circ} \mathrm{C}$ on slopes of nutrient agar. Active cultures of experiment were prepared by transferring a loop full of cells from the stock cultures to test tube of Muller-Hinton broth (MHB) for bacteria that were incubated without agitation for $24 \mathrm{hrs}$ at $37^{\circ} \mathrm{C}$ and $25^{\circ} \mathrm{C}$ respectively. The cultures were diluted with fresh Muller-Hinton broth to achieve optical densities corresponding to $2.0 \cdot 10^{6}$ colony forming units (CFU/ml) for bacteria.

\section{Antimicrobial Susceptibility Test}

The disc diffusion method (Bauer et al., 1966) was used to screen the antimicrobial activity. In vitro antimicrobial activity was screened by using Muller Hinton Agar (MHA) obtained from Hi-media (Mumbai). The MHA plates were prepared by pouring $15 \mathrm{ml}$ of molten media into sterile petriplates. The plates were allowed to solidify for 5 minutes and $0.1 \%$ inoculums suspension was swabbed uniformly and the inoculums were allowed to dry for 5 minutes. The concentration of extracts is $40 \mathrm{mg} / \mathrm{disc}$ was loaded on $6 \mathrm{~mm}$ sterile disc. The loaded disc was placed on the surface of medium and the extract was allowed to diffuse for 5 minutes and the plates were kept for incubation at $37^{\circ} \mathrm{C}$ for $24 \mathrm{hrs}$. At the end of incubation, inhibition zones formed around the disc were measured with transparent ruler in millimeter.

\section{Antifungal Activity}

\section{Culture Media}

The media used for antifungal test was Sabouraud's dextrose agar/broth of Hi media Pvt. Bombay, India.

\section{Determination of Antifungal Activity}

The agar well diffusion method (Perez, 1993) was modified. Sabouraud's dextrose agar (SDA) was used for fungal cultures. The culture medium was inoculated with the fungal strains separately suspended in Sabourauds dextrose broth. A total of $8 \mathrm{~mm}$ diameter disc were placed in the agar and filled with plant extracts. Standard antibiotic (Fucanazole, concentration $1 \mathrm{mg} / \mathrm{ml}$ ) was used as positive control and fungal plates were incubated at $37^{\circ} \mathrm{C}$ for $72 \mathrm{hrs}$. The diameters of zone of inhibition observed were measured.

\section{Results and Discussion}

Antibiotics are most important weapons in fighting bacterial infections and have greatly enhanced the health-related quality of human life since their discovery. But over the past few decades, these benefits are under threat as many commonly used antibiotics have become less effective against certain illnesses not, only because many of them produce toxic reactions, but also due to emergence of drugresistant bacteria. It is essential to investigate newer drugs with lesser resistance. Antimicrobial screening of plant extracts and phytochemicals, then, represents a starting point for antimicrobial drug discovery (Cseke et al., 2016).

In this study, the antimicrobial activity of the methanol extracts of the leaf, stem and flower of Sphenoclea zeylanica at different concentrations was studied using the organisms B. subtilis, P. vulgaris, S. aureus, E. coli, C. albicans, A. niger, S. typhi and B. cereus (Table 1-3). It was seen that the inhibition displayed by the extracts of concentrations 50, 60 and 70 was higher than the inhibition showed by control in some cases. No inhibition was seen at the lowest concentration except for the inhibition of $B$. cereus by the leaf extract. The leaf extract showed maximum antimicrobial activity against the organisms at the highest concentration (Table 1). The most susceptible organisms to the leaf extract were found to be $P$. vulgaris, $C$. albicans, $A$. niger and $B$. cereus. The least susceptible organisms were $S$. aureus and E. coli. Stem extract of Sphenoclea zeylanica had the lowest antimicrobial activity compared to the other two extracts (Table 2). Thus, it can be concluded that the leaves of Sphenoclea zeylanica have significant antimicrobial activity. 
Table 1: Screening of Antimicrobial activity in leaf extract of Sphenoclea zeylanica

\begin{tabular}{|l|l|l|l|l|l|l|}
\hline \multirow{2}{*}{ S.N. } & \multirow{2}{*}{ Organisms } & \multirow{2}{*}{ Control } & \multicolumn{5}{|c|}{ Concentrations } \\
\cline { 5 - 7 } & & & $\mathbf{4 0}$ & $\mathbf{5 0}$ & $\mathbf{6 0}$ & $\mathbf{7 0}$ \\
\hline 1. & B. subtilis & $17 \pm 0.70$ & 0 & $5.66 \pm 1.08$ & $10 \pm 0.70$ & $12 \pm 0.70$ \\
\hline 2. & P. vulgaris & $12.66 \pm 2.16$ & 0 & 0 & $8 \pm 1.41$ & $14.33 \pm 1.47$ \\
\hline 3. & S. aureus & $13.33 \pm 1.47$ & 0 & $4.66 \pm 1.78$ & $7 \pm 1.41$ & $9.66 \pm 1.08$ \\
\hline 4. & E. coli & $13 \pm 1.87$ & 0 & $6 \pm 1.87$ & $8.33 \pm 1.08$ & $11.66 \pm 1.08$ \\
\hline 5. & C. albicans & $16.33 \pm 1.08$ & 0 & $5.66 \pm 2.48$ & $11.33 \pm 1.47$ & $15.66 \pm 1.47$ \\
\hline 6. & A. niger & $16 \pm 1.87$ & 0 & $10 \pm 1.41$ & $10.33 \pm 1.47$ & $17.66 \pm 1.08$ \\
\hline 7. & S. typhi & $16.33 \pm 0.40$ & 0 & $5.33 \pm 1.08$ & $8 \pm 1.87$ & $13.33 \pm 1.08$ \\
\hline 8. & B. cereus & $14 \pm 1.22$ & 0 & $10 \pm 0.70$ & $9.33 \pm 2.16$ & $14.33 \pm 2.27$ \\
\hline
\end{tabular}

Table 2: Screening of Antimicrobial activity in stem extract of Sphenoclea zeylanica

\begin{tabular}{|l|l|l|l|l|l|l|}
\hline \multirow{2}{*}{ S.N. } & \multirow{2}{*}{ Organisms } & \multirow{2}{*}{ Control } & \multicolumn{5}{|c|}{ Concentrations } \\
\cline { 5 - 7 } & & & $\mathbf{4 0}$ & $\mathbf{5 0}$ & $\mathbf{6 0}$ & $\mathbf{7 0}$ \\
\hline 1. & B. subtilis & $17 \pm 0.70$ & 0 & $9 \pm 0.70$ & $13.33 \pm 1.47$ & $13 \pm 0.70$ \\
\hline 2. & P. vulgaris & $12.66 \pm 2.16$ & 0 & $10.33 \pm 1.08$ & $11 \pm 0.70$ & $16 \pm 1.87$ \\
\hline 3. & S. aureus & $13.33 \pm 1.47$ & 0 & $6.66 \pm 1.08$ & $10.66 \pm 0.81$ & $14.33 \pm 1.47$ \\
\hline 4. & E. coli & $13 \pm 1.87$ & 0 & $11.33 \pm 2.27$ & $9 \pm 0.70$ & $11 \pm 0.70$ \\
\hline 5. & C. albicans & $16.33 \pm 1.08$ & 0 & $5.66 \pm 1.47$ & $12 \pm 1.87$ & $14.33 \pm 1.08$ \\
\hline 6. & A. niger & $16 \pm 1.87$ & 0 & $7.66 \pm 1.78$ & $7.66 \pm 1.08$ & $17.33 \pm 1.08$ \\
\hline 7. & S. typhi & $16.33 \pm 0.40$ & 0 & $7 \pm 0$ & $9 \pm 0.70$ & $15 \pm 2.12$ \\
\hline 8. & B. cereus & $14 \pm 1.22$ & 0 & $10 \pm 1.41$ & $14.33 \pm 1.08$ & \\
\hline
\end{tabular}

Table 3: Screening of Antimicrobial activity in flower extract of Sphenoclea zeylanica

\begin{tabular}{|l|l|l|l|l|l|l|}
\hline \multirow{2}{*}{ S.N. } & \multirow{2}{*}{ Organisms } & \multirow{2}{*}{ Control } & \multicolumn{5}{|c|}{ Concentrations } \\
\cline { 4 - 7 } & & & $\mathbf{4 0}$ & $\mathbf{5 0}$ & $\mathbf{6 0}$ & $\mathbf{7 0}$ \\
\hline 1. & B. subtilis & $17 \pm 0.70$ & 0 & $7.33 \pm 1.08$ & $11 \pm 0.70$ & $15 \pm 0.70$ \\
\hline 2. & P. vulgaris & $12.66 \pm 2.16$ & 0 & $6.33 \pm 1.08$ & $11.33 \pm 1.08$ & $11.66 \pm 1.08$ \\
\hline 3. & S. aureus & $13.33 \pm 1.47$ & 0 & $7.66 \pm 0.40$ & $12.66 \pm 1.77$ & $13 \pm 1.41$ \\
\hline 4. & E. coli & $13 \pm 1.87$ & 0 & $7.66 \pm 1.08$ & $13 \pm 1.87$ & $11 \pm 0.70$ \\
\hline 5. & C. albicans & $16.33 \pm 1.08$ & 0 & $11.33 \pm 1.08$ & $11.33 \pm 1.08$ & $18 \pm 0.70$ \\
\hline 6. & A. niger & $16 \pm 1.87$ & 0 & $6.66 \pm 1.08$ & $12.33 \pm 1.08$ & $15 \pm 0.70$ \\
\hline 7. & S.typhi & $16.33 \pm 0.40$ & 0 & $7.33 \pm 0.81$ & $13 \pm 1.41$ & $13 \pm 1.87$ \\
\hline 8. & B. cereus & $14 \pm 1.22$ & 0 & $7 \pm 0.70$ & $8 \pm 0.70$ & $19 \pm 0.70$ \\
\hline
\end{tabular}

\section{Conclusion}

Sphenoclea zeylanica is an herb found commonly in India. In the present study, the methanolic extracts of Sphenoclea zeylanica leaves, flower and stem were analyzed to understand the antimicrobial activity they exhibit. Eight organisms viz B. subtilis, P. vulgaris, S. aureus, E. coli, $C$. albicans, A. niger, S. typhi and B. cereus were taken as test organisms. The most susceptible species were $P$. vulgaris, 
C. albicans, A. niger and B. cereus. The leaf extract had higher antimicrobial activity when compared to other extracts. This study proves that Sphenoclea zeylanica has significant antimicrobial activity. Therefore the compounds can be isolated from this plant and can be developed as antimicrobial agents against microorganisms causing infectious diseases.

\section{References}

Adekunle AS and Adekunle OC (2009) Preliminary assessment of antimicrobial properties of aqueous extract of plants against infectious diseases. Biol. Med. 1(3): 20-24.

Afolayan AJ (2003) Extracts from the shoots of Arctotisarctotoides inhibit the growth of bacteria and fungi. Pharmaceutical Biology 41(1): 22-25. DOI: 10.1076/phbi.41.1.22.14692

Agrios GN (2004) Losses caused by plant diseases Elsevier, Oxford, UK Plant Pathology 29-45.

Ahmad I and Beg AZ (2001) Antimicrobial and phytochemical studies on 45 Indian medicinal plants against multiple drugresistant human pathogens. J. Ethanopharma.74: 113123. DOI: $10.1016 / \mathrm{S} 0378-8741(00) 00335-4$

Akerele O (1993) Summary of WHO Guidelines for the Assessment of Herbal Medicines. 22: 13-28.

Alagesaboopathi C (2011) Antimicrobial Potential and Phytochemical Screening of Andrographis Affinis Nees: An Endemic Medicinal Plant From India. Int. J. Pharma. Pharmaceutical Sci. 3(2): 157- 159.

Balandrin MF, Klocke JA, Wurtele ES and Bollinger WH (1985) Natural plant chemicals Sources of Industrial and Medicinal materials. Science 228: 1154-1160. DOI: 10.1126/science. 3890182

Burt S (2004) Essential oils their antibacterial properties and potential applications in foods: A review. Int. J. Food Microbiol. 94: 223- 253. DOI: 10.1016/j.ijfoodmicro.2004.03.022

Cohen ML (1992) Epidemiology of drug resistance implications for a post antimicrobial era. Science 257: 1050-10510. DOI: $10.1126 /$ science. 257.5073 .1050

Cos P, Vilietinck AJ, VandenBerghe D and Maes L( 2006) Antiinfective potential of natural products: how to develop a stronger in vitro proof-of concept. Journal of Ethanopharmacology 106: 290-302. DOI: 10.1016/j.jep.2006.04.003

Cowan MM (1999) Plant products as antimicrobial agents. Clinical Microbiology Reviews 12(4): 564-582.

Cseke LJ, Kirakosyan A, Kaufman PB, Warber S, Duke JA and Brielmann HL (2016) Natural products from plants. CRC Press.

CSIR (1998) Wealth of India, publications \& information directory. New Delhi, India: CSIR, 164

Ge Y, Difuntorum S, Touami S, Critchley I, Burli R and Jiang V (2002) In vitro antimicrobial activity of GSQ1530, a new heteroaromatic polycyclic compound. Antimicrobial
Agents and Chemotherapy 46(10): 3168-3174. DOI: 10.1128/AAC.46.10.3168-3174.2002

Harbone SB and Baxer H (1995) Phytochemical dictionary A handbook of bioactive compounds from plants Taylor and Francis London.

Harris CA, Renfrew MJ and Woolridge MW (2001) Assessing the risk of pesticide residues to consumers recent and future developments. Food Additives and Contamination 18:1124-1129. DOI: 10.1080/02652030110050122

Kim H, Park SW, Park JM, Moon KH and Lee CK(1995) Screening and isolation of antibiotic resistance inhibitors from herb material Resistant Inhibition of 21 Korean plants. Nat. Prod. Sci. 1: $50-54$.

Kumar B, Vijaykumar M, Govindarajan R and Pushpangadan P (2007) Ethnopharmacological approaches to wound healing-Exploring medicinal plants of India. Journal of Ethnopharmacology $\quad \mathbf{1 1 4}(2): 103-113 . \quad$ DOI: 10.1016/j.jep.2007.08.010

Lewis K and Ausubel FM (2006) Prospects for plant-derived antibacterial Nature. Biotechnology 24(12):1504- 1507. DOI: $10.1038 /$ nbt1206-1504

Nair R and Chanda S (2005) Anticandidal activity of Punica granatum exhibited in different solvents. Pharmaceutical Biology 43(1): 21-25. DOI: 10.1080/13880200590903309

Nascimento G, Juliana Locatelli GF, Paulo C, Freitas G and Silva L (2000) Antibacterial activity of plant extracts and phytochemicals on antibiotic-resistant bacteria. Braz. $J$. Microbiol. 31: 247-256. DOI: 10.1590/S151783822000000400003

Neogi U, Saumya R, Mishra RK, Raju KC (2008) Lipid content and in vitro antimicrobial activity of oil of some Indian medicinal plants Current Research in Bacteriology 1:1-6.

Osman KA and Al-Rehiayam S (2003) Risk assessment of pesticide to human and the environment. Saudi J. Biol. Sci: 10: 81- 106 .

Parekh J, Darshana J and Chanda S (2007) Efficacy of aqueous and methanol extracts of some medicinal plants for Potential antibacterial activity. Turk. J. Biol. 29: 203-210.

Portillo A, Vila R, Freixa B, Adzet T and Canigueral S (2001) Antifungal activity of Paraguayan plants used in traditional medicine. J. Ethnopharmacol. 76: 93-98. DOI: 10.1016/S0378-8741(01)00214-8

Srivastava, J, Lambert J and N Vietmeyer (1996) Medicinal plants: An expanding role in development. World Bank Technical Paper No. 320. 20.

Stranger RN and Scott PR (2005) Plant Disease: A threat to global food security. Annual review of phytopathology 43: 83-11. .DOI: 10.1146/annurev.phyto.43.113004.133839

Suresh G, Ramesh B, Kavitha K, Ravichandran NR, Suresh A, Gopalakrishnaan V and Vijaiyan SG 2010 ) Preliminary screening of antibacterial compounds from Palar river basin flora. Journal of Phytology 2(2): 24-29.

Uniyal SK, Singh KN, Jamwal P and Lal B (2006) Traditional use of medicinal plants among the tribal Candida albicans and 
Neisseria gonorrhoea. J. Ethnobiol Ethnomed 2(1):14-21. DOI: 10.1186/1746-4269-2-14

Usher G (1984) A Dictionary of Plants. CBS Publishers and Distributors, New Delhi.
Zhonghua MA and Michailides TJ (2005) Advances in understanding molecular mechanisms of fungicide resistance and Molecular detection of resistant genotypes in phytopathogenic fungi. Crop Prot. 24: 853-863. DOI: 10.1016/j.cropro.2005.01.011 